\title{
- Knowledge on Lifestyle Modification among Postmenopausal Women
}

IJCRR
Section: Healthcare
ISI Impact Factor
(2019-20): 1.628
IC Value (2019): 90.81
SJIF (2020) = 7.893
C) ()

\section{Mrudula Dalvi', Rutuja Patili ${ }^{1}$, T. Poovishnu Devi'}

'Department of Physiotherapy, Faculty of Physiotherapy, Krishna Institute of Medical Sciences Deemed to be University, Karad, Satara, Maharashtra, India; Department of Cardiopulmonary Sciences, Faculty of Physiotherapy, Krishna Institute of Medical Sciences Deemed to be University, Karad, Satara, Maharashtra, India.

\section{ABSTRACT}

Introduction: Postmenopausal women are those women who have stopped menstrual bleeding one year ago physiologically or as a result of medical or surgical interventions. Postmenopausal women undergo various hormonal, physiological and physical changes. These hormonal changes lead to the development of distressing symptoms including hot flushes, joint pain, sleep disturbances, vaginal dryness, osteoporosis, cardiovascular diseases, etc. The majority of women in India attain menopause with limited knowledge and coping strategies to deal with menopausal symptoms. Lifestyle modification is an easy way to cope up with these menopausal symptoms which involve altering the long term habits, mainly diet, physical activity, etc and maintaining a new behaviour for months or years. Adequate knowledge of lifestyle modification in postmenopausal women can lead to early prevention of menopausal symptoms and complications.

Method: This study was conducted in Karad among 94 postmenopausal women belonging to the age group of 45 to 65 years. The participants were selected according to inclusion and exclusion criteria and a self-administered questionnaire was distributed among them and correct responses were calculated according to 5 points Likert scale.

Result: The study evaluated that out of 94 participants $13 \%(12)$ had good knowledge, 66\% (62) had average and $21 \%(20)$ had poor knowledge regarding lifestyle modification in the postmenopausal period.

Conclusion: This study concluded that most of the postmenopausal women had average knowledge and very few had good knowledge of necessary lifestyle changes to be done after menopause. Hence, knowledge of lifestyle modification proves beneficial in improving the quality of life of postmenopausal women.

Key Words: Knowledge, Lifestyle, Modification, Postmenopausal women, Symptoms, Physical activity

\section{INTRODUCTION}

Menopause is defined as the complete cessation of menstruation for 12 months or more which is a normal physiological change experienced by every woman. The menopausal period is a stage in a women's life that occurs as a result of loss of follicular activity of ovaries that eventually leads to a reduction in oestrogen production. ${ }^{1}$ The average age of natural menopause in Indian women is determined to be $46.2 \pm 4.9$ years. $^{2}$

The onset of menopause leads to the cessation of reproductive function and makes women vulnerable to various healthrelated problems. The normal physiological changes occurring in the reproductive and endocrine system as the women approach menopause leads to hormonal imbalances like re- duction in the level of oestrogen and androgens. ${ }^{3}$ The tissues vulnerable to change as a result of reduced oestrogen level are ovaries, vagina, breast, urinary tract, uterus, in conjunction with these tissues the hypothalamus, skin, cardiovascular tissues and bones may also get affected. ${ }^{4}$ Withdrawal of oestrogen negatively affects the metabolic and cardiovascular health of postmenopausal women. As a result of changes in metabolic function, several adaptations take place in fat accumulation. This leads to a reduction in subcutaneous fat and an increase in abdominal fat. This increases the tendency for obesity and weight gain which in turn increases the risk of hypertension, high blood lipid levels and increasing insulin resistance. $5,6,7,8$

Poor musculoskeletal health leads to greater compromise in quality of life which is increasingly becoming a health

Corresponding Author:

Mrudula Dalvi, Department of Physiotherapy, Faculty of Physiotherapy, Krishna Institute of Medical Sciences Deemed to be University, Karad, Satara, Maharashtra, India; Email: mruduladalvi24@gmail.com

ISSN: 2231-2196 (Print) ISSN: 0975-5241 (Online)

Received: $20.04 .2021 \quad$ Revised: 02.07 .2021

Accepted: 27.08 .2021

Published: 13.12 .2021 
hazard in postmenopausal women. Oestrogen deficiency in this population adversely affects the skeletal system by increasing the rate of bone resorption which further builds up the risk of osteoporosis and fractures. The risk of falls is potentiated by weak muscles, weak joints and frailty and a minor fall also result in fracture due to osteoporotic bones. This further increases the risk of early degenerative changes leading to osteoarthritis. ${ }^{9}$ Apart from this a decline in oestrogen levels leads to the development of various signs and symptoms such as joint pain, depression, fatigue, headache, anxiety, incontinence, constipation, obesity, decrease in bone mineral density, poor concentration, cardiovascular diseases, hot flushes, night sweats, sleep disturbances, mood disturbances, vaginal dryness, etc. ${ }^{10}$ Another important factor that should be focused on by postmenopausal women is the pelvic floor musculature. The volume of the pelvic floor musculature in these women is reduced and they are more liable to the development of urinary incontinence. Pelvic floor exercises should be practised by the women to reduce further complications such as uterine prolapse and incontinence. ${ }^{11}$

There are many modifiable risk factors associated with musculoskeletal health such as low calcium intake, vitamin D deficiency, alcohol intake, smoking, low body mass index, frequent falls, psychological, ergonomic and occupational factors whereas the non-modifiable risk factors include female gender, family history, previous fractures, race or ethnicity, the onset of menopause and prior hysterectomy are all the major risk factors of musculoskeletal disorders. ${ }^{12}$

India has a huge population of approximately 43 million postmenopausal women and the Indian Menopause Society estimated that this number will increase to about 103 million by $2026 .{ }^{13}$ According to WHO the percentage of postmenopausal women residing in developing and industrialized countries will be $76 \%$ and $24 \%$ respectively. Many health care programmes such as Reproductive and Child health II and the National rural health mission focuses mainly on the women in the reproductive age group ignoring those beyond menopause. Hence the health of postmenopausal women demands a greater priority in India. ${ }^{14}$ Majority of women in India attain menopause with limited knowledge and coping strategies to deal with menopausal symptoms. Therefore, increasing the level of awareness about postmenopausal symptoms its complications and management, among postmenopausal women is necessary to reduce their discomfort and improve quality of life. ${ }^{15}$

Postmenopausal women face several challenges in this period, but they have the opportunity to modify their lifestyle and decrease the burden of menopausal symptoms. Even though the physiological changes after menopause and changes that occur as a result of ageing are inevitable, lifestyle behaviours such as lack of physical activity, unhealthy diet, per- sonal habits, etc. are modifiable. ${ }^{16}$ Lifestyle modification involves altering the long term habits, mainly of physical activity, diet, etc. and maintaining a new behaviour for months or years. Lifestyle modification has numerous benefits and it has been proven to reduce the incidence of obesity, risk of cardiovascular diseases, malignancy, osteoporosis, psychiatric disorders, etc.

During this new phase of life, every woman should have adequate knowledge of symptoms and must know the importance of lifestyle modification to cope up with the symptoms and have a better quality of life. Hence the knowledge of lifestyle modification and health maintenance is necessary for establishing a better health status. Awareness of modifying lifestyle after menopause can reduce the risk of diseases and thereby aid in minimizing the medical costs related to disease management. Adequate knowledge and implementation of this knowledge about lifestyle modification in postmenopausal women can lead to early prevention of menopausal symptoms and complications. Hence this study was conducted to assess Knowledge of Lifestyle modification in postmenopausal women.

\section{MATERIAL AND METHOD}

This observational study was conducted among 94 postmenopausal women between the age group of 45 to 65 years. The study was conducted in Karad. Participants were selected according to inclusion and exclusion criteria.

\section{Inclusion criteria}

1. Women between the ages of 45 to 65 years.

2. Women suffering from symptoms of menopause.

3. Women who are not taking any sort of treatment for menopause.

\section{Exclusion criteria}

1. Women with healthy postmenopausal life.

2. Women who were not willing to participate in the study.

\section{Sample size}

The sample size was calculated according to the formula: $\mathrm{n}=\frac{4 p q}{L^{2}}$

$$
\begin{gathered}
\text { Where: } \mathrm{p}=38 \% \mathrm{q}=62 \% \mathrm{~L}=10 \% \\
\mathrm{n}=\frac{(4)(38 \times 62)}{(10)^{2}} \\
\mathrm{n}=94
\end{gathered}
$$

$\mathrm{n}=$ sample size

$\mathrm{p}=$ relative population of positive knowledge

$\mathrm{q}=$ No positive knowledge $=(100-\mathrm{p})=62 \%$

$\mathrm{L}=$ Allowable error of $95 \%$ confidence interval $=10 \%$ 
The ethical clearance was given by the ethical committee of KIMSDTU Karad. Ethical clearance no. 0124/20192020 and after obtaining a signed informed consent form, the questionnaire was distributed among participants and the data was collected according to inclusion and exclusion criteria. A structured questionnaire to assess Knowledge of Lifestyle modification among Postmenopausal women. The questionnaire assessed knowledge in three domains mainly physical activity, diet and personal habits. A total of 94 postmenopausal women aged between 45 to 65 years were included in the study. The mean age of women was $55.5 \pm 5.61$ years. The mean duration of menopause was 9.3 years. Out of 94 postmenopausal women, 42 women were literate with most of them having primary education and 52 women were illiterate. 16 women had undergone surgical menopause and the remaining 78 had natural menopause. The cause of surgical menopause was abnormal menstrual bleeding, uterine fibroid, and ovarian mass.

The scoring was done according to 5 points Likert scale, where the highest score was considered as good knowledge and the lowest score as poor knowledge. The response for each question was: Strongly agree, Agree, Neutral, Disagree and strongly disagree. The good average and poor scores were calculated according to mean and standard deviation.

\section{RESULT}

The statistical analysis was done by using Instant (Graphpad 3) software. Arithmetic mean and standard deviation was calculated for categorizing the responses as good, average and poor. MS Excel was used for data analysis and plotting graphs.

Table 1. Out of 94 participants, 12 (13\%) women had good knowledge, 62(66\%) women had average and 20(21\%) women had poor knowledge regarding lifestyle modification. (Fig.1) The mean score of knowledge was 50.96 and the standard deviation was 13.25.

Table 2. interprets the association of knowledge with age. 44 Postmenopausal women were up to the age of 55 years out of which $8(18 \%)$ women had good knowledge, 29(66\%) women had average and 7(16\%) women had poor knowledge of lifestyle modification. 50 postmenopausal women belonged to the age group of $>55$ years out of which the knowledge score of 4(8\%) postmenopausal women was good, 33(66\%) women had average knowledge and 13(26\%) women were under the category of poor knowledge. The comparison of knowledge scores between two age groups evaluated that the women above the age of 55 years were having less knowledge as compared to those below 55 years of age. (Fig.2)

Table 3. reveals that the total number of participants was 94 out of which duration of menopause of 60 participants was in between 1 to 10 years, with $8(13 \%)$ participants having good knowledge,40(67\%) having average and $12(20 \%)$ having poor knowledge. 30 participants were included in the group of 11 to 20 years of menopause duration from which $4(13 \%)$ participants had good knowledge, $19(64 \%)$ had average knowledge and $7(23 \%)$ had poor knowledge regarding lifestyle modification. Only 4 participants had more than 20 years of duration of menopause among them none had good knowledge, 3(70\%) had average knowledge and 1(30\%) participants had poor knowledge of lifestyle modification after menopause. (Fig.3) The Chi-square value was 0.7505 and P-value was 0.9450 . The knowledge scores when compared according to the duration of menopause it was found that there was no significant difference in scores.

\section{DISCUSSION}

With increasing life expectancy women spend about $1 / 3$ of their life in the postmenopausal phase. The average age of menopause in Indian women is 46.2 years so they could spend on average 30 years in the post-menopausal stage of their life. Due to oestrogen deficiency, postmenopausal women are at risk of developing cardiovascular diseases, osteoporosis, cancer, etc. However, to deal with the distressing symptoms that develop after menopause, knowledge regarding lifestyle modification can be beneficial in reducing the severity of symptoms. The present study was conducted to assess Knowledge of lifestyle modification among postmenopausal women, which included 94 postmenopausal women in between the age group of 45 to 65 years from Karad.

The result of the present study evaluated that $13 \%$ of postmenopausal women had good knowledge, $66 \%$ had average and $21 \%$ had poor knowledge regarding lifestyle modification. As $55 \%$ of women were illiterate the overall good knowledge score was only $13 \%$. In contrast to the present study, a study conducted by Jacintha Veigas et al. on Knowledge and Practice of postmenopausal women on health maintenance in rural communities of Mangalore evaluated that $75 \%$ of participants had good knowledge of health maintenance in the postmenopausal period.$^{17}$

Among 94 postmenopausal 51.06\%, women felt that apart from doing household work extra physical activity is necessary after menopause. $76.59 \%$ of women were unaware that relaxation techniques can aid in reducing psychological symptoms of menopause. After assessing the knowledge regarding personal habits it was found that $66.30 \%$ of women did not know that quitting the use of tobacco is essential in the postmenopausal period of life. $55 \%$ of women knew that consuming a diet rich in calcium is important beyond menopause. Out of total women, half of the postmenopausal women knew about including soy protein in the diet. $73 \%$ of 
participants were unaware of consulting physicians for their symptoms.

The present study observed that $48 \%$ of women agreed that 'regular exercise can build up strong bones' similar to this study a study conducted by Nirmal Raj Gopinathan et al. on Awareness of osteoporosis in postmenopausal women concluded that $48 \%$ of women agreed that regular exercise helps to build up strong bones. ${ }^{18}$ Our study evaluated that the mean score of the physical activity domain was $21.05 \pm 5.80$. In contrast to this, another study done on health-promoting lifestyle behaviours in menopausal women conducted by Fereshte Shabani Asrami et al. showed that the mean score of the physical activity subscale was $16.12 \pm 4.30$.

The present study evaluated that $35 \%$ women agreed that regular exercise helps maintain a healthy heart, $40 \%$ of participants had knowledge that slow, deep and meditative breathing helps deal with insomnia, $35 \%$ of women knew avoiding caffeine and heavy meals before bedtime in contrast to this study, the previous study done by Dr. Chandrashree Lenka on Knowledge, practice and lifestyle management of postmenopausal women observed that $77 \%$ of women knew that doing regular exercise is essential for keeping healthy heart, $13 \%$ were aware of the usefulness of deep, slow and meditative breathing for reducing insomnia, only $5 \%$ of participants knew avoiding caffeine and heavy meals before bedtime. ${ }^{19}$

The present study evaluated that $21 \%$ of postmenopausal women had poor nutritional knowledge, similar to this study a study conducted by LW Pon et al. on diet, nutritional knowledge and health status of middle-aged women showed that $20 \%$ of postmenopausal women had poor knowledge on nutrition. ${ }^{20}$ The knowledge of foods to be consumed after menopause in our study was ranging between $16 \%$ to $21 \%$ in contrast to this study a study conducted by Sugunadevi $\mathrm{G}$ et al. on Health education programs about postmenopausal changes showed that the awareness of foods to be consumed was ranging from $38 \%$ to $52 \% .{ }^{21}$ The present study observed that $53 \%$ of women knew reducing fat intake $21 \%$ had knowledge of consuming high fibre diet whereas $55 \%$ of women knew taking calcium-rich food in the diet, in contrast to this study the above study showed that $44 \%$ of women knew reducing fat intake, $52 \%$ knew taking high fibre diet and $38 \%$ of women knew taking calcium-rich food in the diet.

The menopausal period is a transition phase in a women's life i.e. the transition occurs from fertility to infertility. During this transition phase, numerous alterations occurring in the hormonal levels propel the women into various healthrelated issues. Lifestyle modification is beneficial in the prevention of these complications and will help reduce the economical burden on the individual. Many health issues can be prevented or delayed if women have appropriate knowledge regarding lifestyle modification and they can continue to live an active healthy life after menopause. Modifying the lifestyle of postmenopausal women will not only reduce the problems of postmenopausal women but also reduce the burden over their family and in turn on society. Hence, adequate knowledge of lifestyle modification can be beneficial in reducing the severity of symptoms and improving the quality of life of postmenopausal women.

\section{CONCLUSION}

This study concluded that most of the postmenopausal women had average knowledge and very few had good knowledge of necessary lifestyle changes to be done after menopause

\section{ACKNOWLEDGEMENT}

We acknowledge our university, Krishna Institute of Medical Sciences Deemed to be University for permitting us to conduct the study. We would also like to thank our guide Dr. T. Poovishnu Devi and Dean Dr. G. Varadharajulu for their guidance and support. We would also like to thank the participants for their active participation in the study.

Source of Funding: Krishna Institute of Medical Sciences Deemed to be University Karad.

Conflict of Interest: No conflict of interest.

\section{Authors' Contribution:}

Mrudula Dalvi prepared the result and discussion for the study Rutuja Patil conducted the literature review and Dr. Poo. Vishnudevi helped in preparing the background. Mrudula and Rutuja collected the samples and analysed the data. All three authors finalised the manuscript.

\section{REFERENCES}

1. Burger HG. Physiology and endocrinology of the menopause. Medicine. 2006 Jan 1; 34(1):27-30.

2. Ahuja M. Age of menopause and determinants of menopause age: A PAN India survey by IMS. J Mid-life Health. 2016 Jul; 7(3):126.

3. Shakhatreh FM, Mas' ad D. Menopausal symptoms and health problems of women aged 50-65 years in Southern Jordan. Climacteric. 2006 Jan 1;9(4):305-11.

4. Utian WH. Biosynthesis and physiologic effects of estrogen and pathophysiologic effects of estrogen deficiency: a review. Am. J. Obstet. Gynecol. 1989 Dec 1; 161(6):1828-31.

5. Mason C, Foster-Schubert KE, Imayama I, Kong A, Xiao L, Bain C, et al. Dietary weight loss and exercise effects on insulin resistance in postmenopausal women. Am. J. Prev. Med. 2011 Oct 1;41(4):366-75.

6. Garcia M, Mulvagh SL, Bairey Merz CN, Buring JE, Manson JE. Cardiovascular disease in women: clinical perspectives. Circulation research. 2016 Apr 15;118(8):1273-93. 
7. Sun Y, Liu B, Snetselaar LG, Wallace RB, Caan BJ, Rohan TE, Neuhouser ML, Shadyab AH, Chlebowski RT, Manson JE, Bao W et al. Association of normal-weight central obesity with all-cause and cause-specific mortality among postmenopausal women. JAMA Network Open. 2019 Jul 3;2(7):e197337.

8. Lizcano F, Guzmán G. Estrogen deficiency and the origin of obesity during menopause. BioMed research international. 2014 Oct; 2014.

9. Mishra SK. Menopausal transition and postmenopausal health problems: a review on its bio-cultural perspectives. Health. 2011 Apr 29; 3(04):233.

10. Ikeme AC, Okeke TC, Akogu SP, Chinwuba N. Knowledge and perception of menopause and climacteric symptoms among a population of women in Enugu, South East, Nigeria. Annals of medical and health sciences research. 2011; 1(1):31-6.

11. Frota IP, Rocha AB, Neto JA, Vasconcelos CT, De Magalhaes TF, Karbage SA, Augusto KL, Nascimento SL, Haddad JM, Bezerra LR et al. Pelvic floor muscle function and quality of life in postmenopausal women with and without pelvic floor dysfunction. Acta obstetricia et Gynecologica Scandinavica. 2018 May;97(5):552-9.

12. Khadilkar SS. Musculoskeletal disorders and menopause.

13. Kashyap A, Chhabra P. Assessment of Nutritional Intake and Nutritional Knowledge of Rural Post-Menopausal Women.

14. Borker SA, Venugopalan PP, Bhat SN. Study of menopausal symptoms, and perceptions about menopause among women in a rural community in Kerala. J Mid-life Health. 2013 Jul;4(3):182.

15. Saswatika Beura, Lipilekha Patnaik, Manisha Sahoo, Sumitra Pattanaik. Assessment of Knowledge, Attitude and Prac- tices towards menopause among postmenopausal women - A Cross-sectional study. ijrps [Internet]. 2020Sep.23 [cited 2021Aug.5];11(4):5134-40. Available from: https://pharmascope.org/index.php/ijrps/article/view/3117

16. Rathnayake N, Alwis G, Lenora J, Mampitiya I, Lekamwasam S. Effect of Health-Promoting Lifestyle Modification Education on Knowledge, Attitude, and Quality of Life of Postmenopausal Women. BioMed Res Int. 2020 May 20;2020.

17. Viegas J, Nagar N, Deralakatte M, Sudhakar C. Factors influencing health practices of postmenopausal women in a selected rural community of Mangalore, Dakshina Kannada district, Karnataka.

18. Gopinathan NR, Sen RK, Behera P, Aggarwal S, Khandelwal $\mathrm{N}$, Sen M. Awareness of osteoporosis in postmenopausal Indian women: An evaluation of Osteoporosis Health Belief Scale. J Mid-life Health. 2016 Oct;7(4):180.

19. Chandrashree L. Knowledge, practice and lifestyle management of postmenopausal women: A study in Odisha. Int J Home Sci 2016; 2(3):80-84.

20. Pon LW, Noor-Aini MY, Ong FB, Adeeb N, Seri SS, Shamsuddin K, Mohamed AL, Hapizah N, Mokhtar A, Wan HW. Diet, nutritional knowledge and health status of urban middle-aged Malaysian women. Asia Pac J Clin Nutr. 2006 Sep 1; 15(3).

21. Sugunadevi G, Divya BV. Health education program about postmenopausal changes to perimenopausal women in an urban slum area, Coimbatore. Int J Med Sci Public Health. 2018 Mar $1 ; 7(3): 193-8$.

Table 1: Total knowledge score interpreted in form of frequency and percentage.

\begin{tabular}{lcc} 
SCORE & Frequency & Percentage \\
GOOD & 12 & $13 \%$ \\
AVERAGE & 62 & $66 \%$ \\
POOR & 20 & $21 \%$ \\
\hline
\end{tabular}

Table 2: Association of knowledge with age and Chi-square and P-value

\begin{tabular}{lllllllll}
$\begin{array}{l}\text { AGE } \\
\text { (in years) }\end{array}$ & \multicolumn{4}{c}{ KNOWLEDGE } & \multicolumn{3}{c}{ Chi-square } & P-value \\
& GOOD & \multicolumn{3}{c}{ AVERAGE } & POOR & & \\
& F & $\%$ & F & $\%$ & F & $\%$ & & \\
Up to 55 years & 8 & $18 \%$ & 29 & $66 \%$ & 7 & $16 \%$ & \multirow{2}{*}{3.021} & 0.2208 \\
$>55$ years & 4 & $8 \%$ & 33 & $66 \%$ & 13 & $26 \%$ & & \\
\hline
\end{tabular}

F= Frequency \%= Percentage

Table 3: Association of Knowledge with duration of menopause and Chi-square and P-value

\begin{tabular}{|c|c|c|c|c|c|c|c|c|c|}
\hline \multirow{3}{*}{$\begin{array}{l}\text { Duration of meno- } \\
\text { pause } \\
\text { (in years) }\end{array}$} & \multirow{3}{*}{$\begin{array}{c}\text { FREQUENCY } \\
\text { (n) }\end{array}$} & \multicolumn{6}{|c|}{ SCORE } & \multirow[t]{3}{*}{ Chi-square } & \multirow[t]{3}{*}{ P-value } \\
\hline & & \multicolumn{2}{|c|}{ GOOD } & \multicolumn{2}{|c|}{ AVERAGE } & \multicolumn{2}{|c|}{ POOR } & & \\
\hline & & $\mathbf{F}$ & $\%$ & $\mathbf{F}$ & $\%$ & $\mathbf{F}$ & $\%$ & & \\
\hline 1 to 10 years & 60 & 8 & $13 \%$ & 40 & $67 \%$ & 12 & $20 \%$ & & \\
\hline 11 to 20 years & 30 & 4 & $13 \%$ & 19 & $64 \%$ & 07 & $23 \%$ & 0.7505 & 0.9450 \\
\hline$>20$ years & $\mathrm{O} 4$ & o & o\% & 03 & $30 \%$ & o1 & $70 \%$ & & \\
\hline
\end{tabular}

$\mathrm{F}=$ Frequency $\%=$ Percentage 


\section{TOTAL KNOWLEDGE}

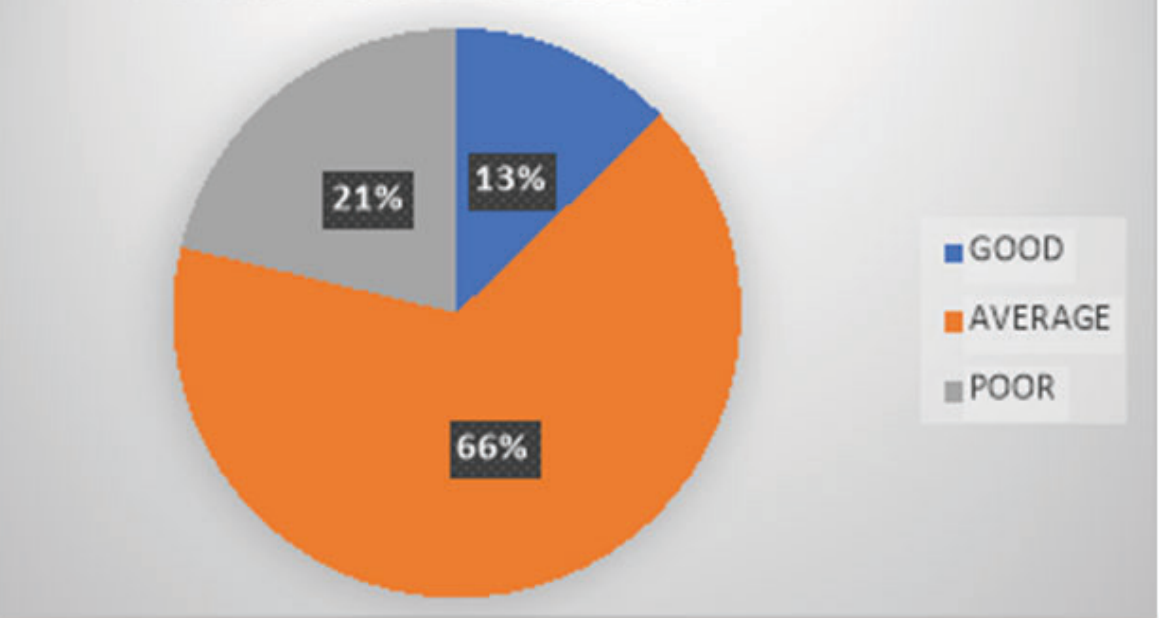

Figure 1: Total knowledge score in percentage showing good, average and poor knowledge.

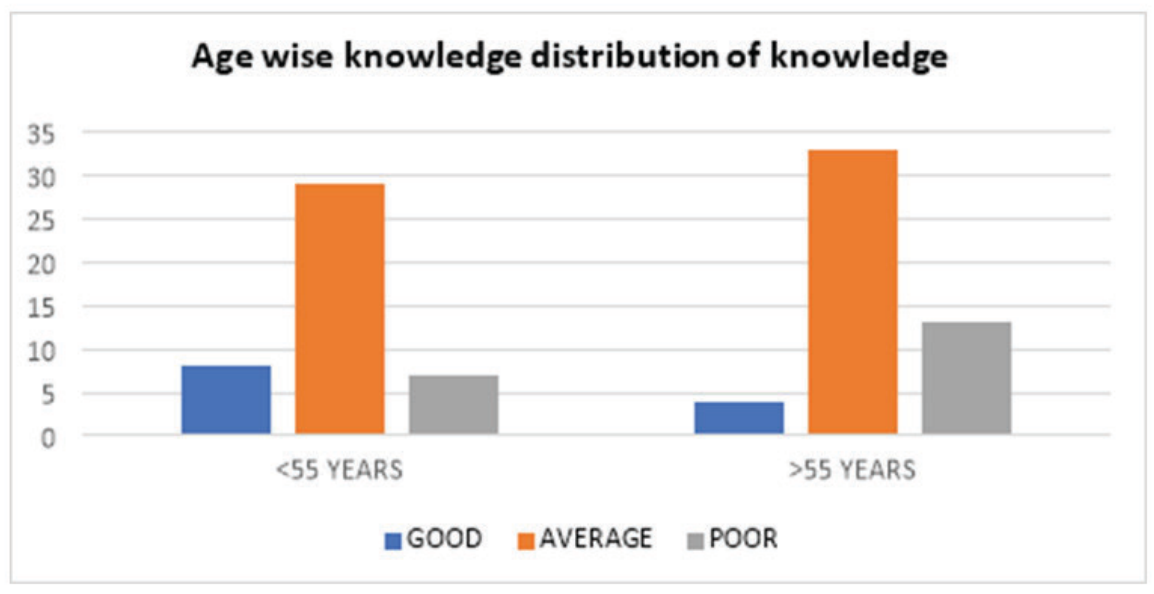

Figure 2: Age wise distribution of knowledge according to percentage.

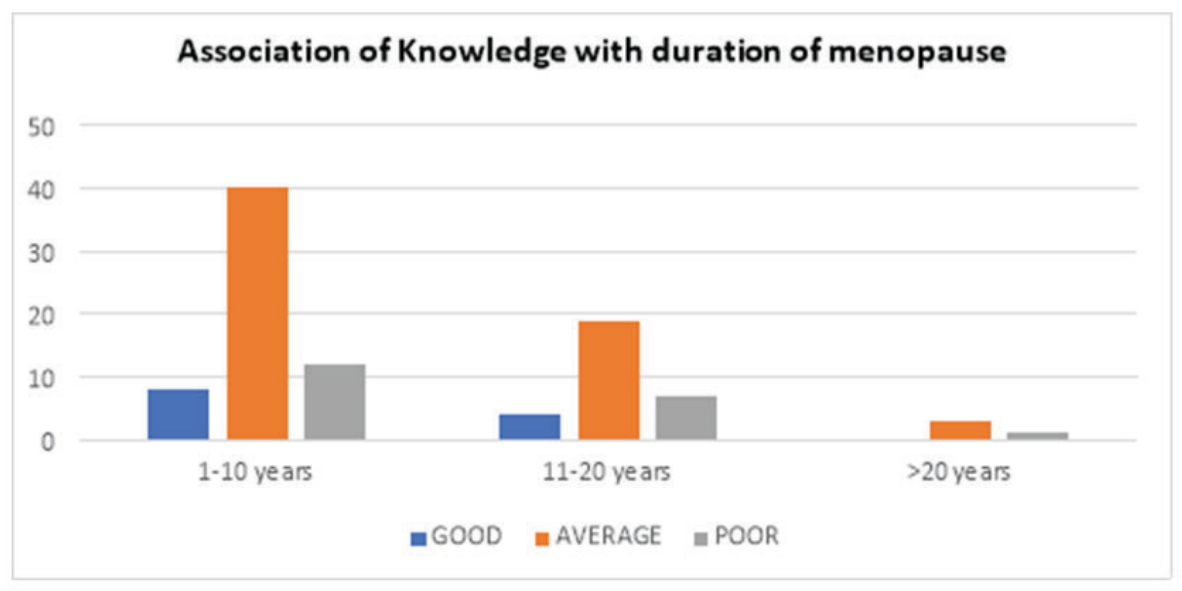

Figure 3: Association of knowledge with the duration of menopause. 